Journal of Mathematics and Informatics

Vol. 14, 2018, 79-87

ISSN: 2349-0632 (P), 2349-0640 (online)

Published 15 December 2018

www.researchmathsci.org

DOI: http://dx.doi.org/10.22457/jmi.v14a10

Journal of

Mathematics and

Informatics

\title{
The Impact of Error Management Climate on Employee Performance
}

\author{
Yin-ping Guan ${ }^{1}$, Liang-ru $\mathrm{Yu}^{2}$ and Chong-li Wang ${ }^{3}$ \\ School of Economics and Management \\ Chongqing University of Posts and Telecommunications, Chongqing, China \\ ${ }^{1}$ E-mail: guanyinping123@foxmail.com; ${ }^{2}$ E-mail: yuliangru@qq.com \\ ${ }^{3}$ E-mail: $1763256864 @ q q . c o m$
}

Received 5 November 2018; accepted 13 December 2018

\begin{abstract}
Based on organizational learning theory, using the sample of 1400 questionnaires, we text the impact of organizational error management climate on employee performance under the Chinese context. The results show that the positive error management climate directly affects the employee's contextual performance; the negative error management climate directly affects the employee's task performance.
\end{abstract}

Keywords: error management climate; contextual performance; task performance

AMS Mathematics Subject Classification (2010): 90Bxx

\section{Introduction}

In a fiercely competitive environment, firms not only need employees who know to "do things", but also need employees who know to "think things". It means that employees must not only have high task performance, but also high contextual performance (such as cooperation, help, and completing the additional tasks spontaneously). In order to improve work performance or not be eliminated by firms, employees tend to tense work, think, explore, and seek breakthroughs [1]. These behaviors are characterized by workload overload, capacity overload, cognitive overload and uncertainty, making that every employee is confronted with errors [1]. Errors can lead to negative emotions and work pressures. especially in the Internet information age, errors of some well-known brands will spread, diffuse and amplify speedly through network channels, suffering heavy losses, and even sustaining a fatal pressure. But, from another perspective, errors are misplaced resources, and errors can provide employees with opportunities that can help employees rethinking themselves, knowing shortcomings, improving work methods, providing error feedback, and learning from error [2]. Therefore, it is important to explore the impact of error management climate on employee performance.

Present researches on error management climate and performance focuse on the organizational level, and less on the individual level [3]. For organizational performance, van Dyck et al. show that the error management culture can produce positive consequences for learning and innovation, optimizing workflow, and ultimately Improving corporate performance [2]; Fruhen and Keith found out that in low-risk and high-risk situations, error management culture, error-averse culture and task cohesion 


\section{Yin-ping Guan, Liang-ru Yu and Chong-li Wang}

have a significant impact on team safety performance, and error management culture mediates the relationship between team task cohesion and accident rate [4]; Zhu and Bai believe that the positive error management culture plays a positive role in organizational performance through technological innovation and management innovation[5]. For individual performance, Du and Huang using 343 questionnaires find that the error management culture can promate employee task performance and contextual performance through organizational identity [6]. In view of this, we construct and text the impact of error management climate on employee performance under the Chinese context. We hope to provide reference for the organization's error management and employee performance management practices, and further help firms to turn employees' errors, lessons into useful resources.

\section{Concept definition and research hypothesis}

\subsection{Error management climate}

An error is when an individual's behavior unconsciously deviates from the goal or plan [7]. The error management climate is the organizational practices, procedures, and attitudes related to errors, that is, the ways and means of organizing errors $[2,8]$. The error management climate can be divided into two dimensions, namely positive (tolerance, learning orientation) and negative (disgust, punishment-oriented) error management climate $[2,4,9,10]$.

The positive error management climate does not limit the occurrence of errors [2], similar to the loose organizational culture [9]. In the positive error management climate, employees will actively conduct error communication, think about the cause of the error, and propose a new solution $[2,4]$. The negative error management climate does not allow employees to make mistakes [2], similar to a serious organizational culture [9]. In the negative error management climate, employees will take measures and behaviors to prevent mistakes, obey organizational orders, and abide by rules and regulations [8], and promote the organization and management of the model.

\subsection{Dual performance}

According to Borman and Motowidle's views, in addition to behaviors that directly affect the core of organizational technology, job performance also includes off-role behaviors that are indirectly at the core of organizational technology, and builds a two-dimension model of job performance, namely task performance and contextual performance (peripheral performance) [11]. This important discovery provides the basic framework for future scholars to love. Subsequently, Wang Hui et al. verified through empirical analysis that task performance and contextual performance can be separated in the Chinese context [12]. Task performance is performance related to the work and tasks specified by the organization [11,13]. It is a behavior within a role that emphasizes the behavioral outcomes of employees within their job duties $[11,14]$. Contextual performance is an altruistic act that employees voluntarily take the tasks beyond the requirements of organization's rules and regulations [11,13]. It is an extra-role behavior that emphasizes behavioral outcomes beyond the scope of work $[11,15]$.

\subsection{Research hypothesis}

Whether in the workplace or in life, mistakes are always considered bad. Errors are a 
The Impact of Error Management Climate on Employee Performance

natural consequence of human behavior and are more common in complex systems [2]. For employees, learning from mistakes is an important activity that helps organizations and companies understand the causes and recommendations of employees' mistakes and guide employees' work practices [16].

As the main subject of the organization, the employee's dual performance is deeply influenced by organizational culture [6]. Liu et al.'s research shows that a high organizational culture creats open communication easier, make decision more timely and effectively, and helps employees to divergent thinking and improve performance [17]. According to the organizational learning theory [18], we believe that the positive error management climate has a positive impact on contextual performance by creating a twoloop learning environment. The positive error management climate encourages employees to make mistakes and expresses tolerance and sympathy to the wrong employees [2], which is consistent with the "sympathy" of the leading values of Shuanghuan learning [18], thus contributing to the employees' double-loop learning behavior. Double-loop learning tends to break through paradigm learning, which is consistent with the behavior of contextual performance [11]. That is to say, double-loop learning can promote the active, flexible and autonomous thinking of its actors, and help employees to break through the existing activities within the framework [18], for example, actively participate in error talks and exchanges, actively help the wrong colleagues, and actively maintain Organizational culture, etc., which is conducive to the realization of employee's situational performance [11].

Negative error management climate has a positive impact on task performance by creating a single-loop learning environment. In negative error management climate, organizations punish employees making mistakes more seriously [2,9], prompting employees to form a sense of "absolutely can not make mistakes, hate making mistakes". Therefor, employees will fall into defensive single-ring learning System [18]. Single-loop learning tends to be in-paradigm learning, consistent with the behavioral behavior of task performance [11]. Namely, single-loop learning can encourage its actors to form closed, conservative, and cautious ideas that help employees take behavioral activities within the existing framework [18]. For example, support their status, prove their ability, and rationally complete the tasks the job responsibilities, thus contributing to the achievement of the employee's task performance.

Therefore, this study proposes the following assumptions:

H1: Positive error management climate has a positive impact on contextual performance. $\mathrm{H} 2$ : Negative error management climate has a positive impact on task performance.

Based on the above theoretical basis and assumptions. In addition, Yingjun Zhu and Yu Hao set the gender, age, and education level as control variables in the model of texting the mechanism of between management culture and employee innovation behavior. In actual work, the employee's income is closely related to the employee's work performance. [19]. Referring to the research that is related to our topics, we consider these variables such as gender, age, education level and monthly income as control variables. The conceptual model of the research in this paper is shown in Figure 1: 
Yin-ping Guan, Liang-ru Yu and Chong-li Wang

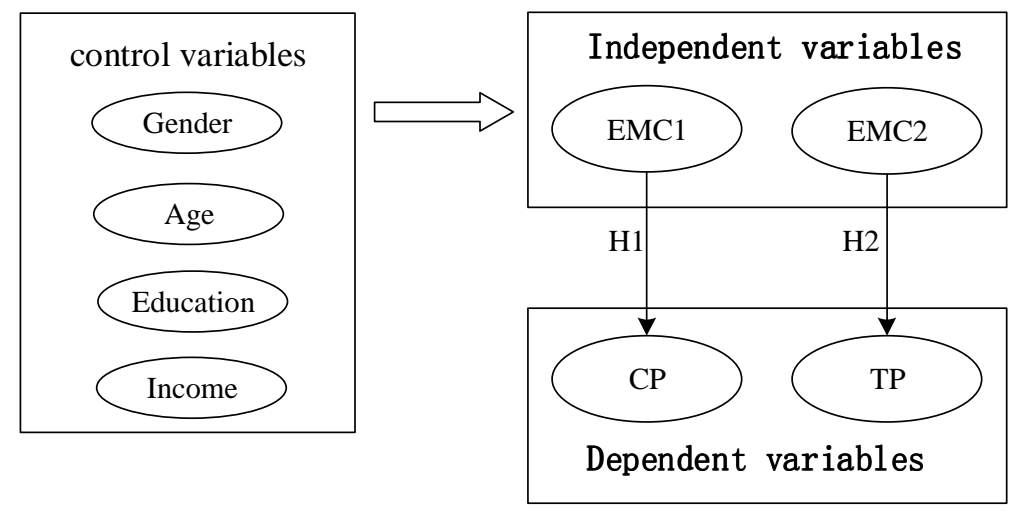

Figure 1: Conceptual model

\section{Data analysis}

\subsection{Research design}

The respondent of this study is the employees of a branch company of China Telecom Group Corporation. Through the company's internal online survey system, the questionnaires were collected and 3176 questionnaires were collected. After eliminating the invalid questionnaires, a total of 1400 valid questionnaires were retained, with an effective rate of $44.1 \%$. The questionnaire uses a 6-point scale. "1" is very inconsistent and "6" is very consistent. The survey involves 11 district and county branches, 4 main city branches and 4 municipal functional departments. Sample characteristics are shown in Table 1.

Table 1: Sample characteristics table

\begin{tabular}{|c|c|c|c|c|c|c|c|}
\hline Feature & Category & $\begin{array}{c}\text { Frequen } \\
\text { cy }\end{array}$ & $\begin{array}{c}\text { Percent } \\
(\%)\end{array}$ & Feature & Category & $\begin{array}{c}\text { Freque } \\
\text { ncy }\end{array}$ & $\begin{array}{l}\text { Perce } \\
\text { nt }(\%)\end{array}$ \\
\hline \multirow{2}{*}{ Gender } & Male & 708 & 50.57 & \multirow{6}{*}{$\begin{array}{l}\text { Age } \\
\text { (old) }\end{array}$} & $<=22$ & 3 & 0.21 \\
\hline & Female & 692 & 49.43 & & $22-25$ & 101 & 7.21 \\
\hline \multirow{4}{*}{ Education } & $\begin{array}{c}<=\text { High } \\
\text { education }\end{array}$ & 106 & 7.57 & & $26-30$ & 320 & 22.86 \\
\hline & Junior college & 660 & 47.14 & & $31-40$ & 553 & 39.50 \\
\hline & Bachelor degree & 601 & 42.93 & & $41-50$ & 348 & 24.86 \\
\hline & >=Master degree & 33 & 2.36 & & $>=50$ & 75 & 5.36 \\
\hline \multirow{5}{*}{$\begin{array}{l}\text { Income } \\
\text { (yuan) }\end{array}$} & $<=2000$ & 79 & 5.6 & \multirow{5}{*}{ Firm } & Main-city branches & 475 & 33.93 \\
\hline & $2000-3000$ & 532 & 38.00 & & Municipal & & \\
\hline & $3000-4000$ & 449 & 32.07 & & $\begin{array}{l}\text { functional } \\
\text { departments }\end{array}$ & 215 & 15.36 \\
\hline & $4000-5000$ & 209 & 14.93 & & district and county & 710 & 50.71 \\
\hline & $>=5000$ & 131 & 9.36 & & & & \\
\hline
\end{tabular}

The measurement of error management climate refers to the scale of previous 
The Impact of Error Management Climate on Employee Performance

researchs [20,21], including 14 items; the measurement of employee work performance mainly refers to the scale of Guoquan [22] and Tsui et al. [23], including situational performance and task performance, a total of 8 items.

The Cronbach's $\alpha$ reliability coefficients of the four variables are all above 0.8 , and the internal consistency reliability is better. The normalized factor load of each item is 0.7 or more, and the significance level is that $\mathrm{P}<0.001$, and the convergence efficiency is better. The correlation coefficient of each factor plus or minus twice the standard error (ie, the $95 \%$ confidence interval of the correlation coefficient) does not include 1 or -1 , indicating a good discriminant validity (Table 3 ). The fitting index of the multi-factor model is that $\chi 2(528)=2502.378, \chi 2 / \mathrm{df}=4.739$, RMSEA $=0.052, \mathrm{NNFI}=0.986, \mathrm{CFI}=0.989$, $\mathrm{IFI}=0.989$, GFI=0.910, AGFI=0.886, although $\chi 2 / \mathrm{df}$ more than 3 , does not meet the judgment criteria. But the expert in the field of structural equations, Jietai Hou and others, think that when $\mathrm{N}$ is large, $\chi^{2}$ is very large, and $\chi 2 / \mathrm{df}$ is of little significance for evaluating a single model [24]. Therefore, our model fits well.

In addition, the fitting results of the Harman single-factor model are shown in Table 2. There is a significant difference between the fitting results of the multi-factor model $(\Delta \chi 2(\mathrm{df})=440.064(66), \mathrm{P}<0.001)$, indicating that one latent variable cannot be used to explain all the factors. Therefore, the homology error of the data is not serious. There was a significant correlation between the error management climate and the employee's binary performance $(\mathrm{P}<0.001)$, indicating that it is suitable for subsequent analysis. A descriptive statistical analysis of the variables is shown in Table 3.

Table 2: Single-factor model analysis

\begin{tabular}{ccccccccc}
\hline$\chi^{2}$ & df & $\chi^{2} / \mathrm{df}$ & RMSEA & NNFI & CFI & IFI & GFI & $\begin{array}{c}\text { AGF } \\
\text { I }\end{array}$ \\
\hline 31546.583 & 594 & 53.109 & 0.193 & 0.809 & 0.820 & $\begin{array}{c}0.82 \\
0\end{array}$ & 0.444 & $\begin{array}{c}0.37 \\
6\end{array}$ \\
\hline
\end{tabular}

Table 3: Descriptive statistical analysis

\begin{tabular}{ccccccc}
\hline Variables & 1 & 2 & 3 & 4 & 5 & 6 \\
\hline 1 Age & 1 & & & & & \\
2 Income & 0.049 & 1 & & & & \\
3 EMC1 & $-0.104^{* * *}$ & -0.005 & 1 & & & \\
4 EMC2 & -0.037 & -0.036 & $0.605^{* * *}$ & 1 & & \\
5 CP & $0.089^{* * *}$ & $0.163^{* * * *}$ & $0.480^{* * *}$ & $0.376^{* * *}$ & 1 & \\
6 TP & 0.025 & $0.129^{* * * *}$ & $0.412^{* * *}$ & $0.335^{* * *}$ & $0.731^{* * * *}$ & 1 \\
Mean & 36.391 & 3343.571 & 4.864 & 4.637 & 5.143 & 5.218 \\
SD & 8.196 & 1051.478 & 0.737 & 1.089 & 0.670 & 0.681 \\
\hline
\end{tabular}

Note: $\mathrm{N}=1400 ; * \mathrm{p}<0.05, * * \mathrm{p}<0.01, * * * \mathrm{p}<0.001 ; \mathrm{SD}$ indicates standard deviation.

\subsection{Empirical results}

This study used SPSS software to test the relationship between independent variables, control variables and dependent variables through regression analysis, including four regression models. Among them, the relationship model between control variables (gender, education, income and age) and employee contextual performance is shown in 
Equation 1.

$\mathrm{CP}=\alpha_{1}+\beta_{11} \mathrm{SEX}+\beta_{12} \mathrm{EDU}+\beta_{13} \mathrm{AGE}+\beta_{14} \mathrm{INCOME} ;$

The relationship between control variables (gender, education, income, and age), positive error management climate, and employee contextual performance is shown in Equation 2.

$$
\mathrm{CP}=\alpha_{2}+\beta_{21} \mathrm{SEX}+\beta_{22} \mathrm{EDU}+\beta_{23} \mathrm{AGE}+\beta_{24} \mathrm{INCOME}+\beta_{25} \mathrm{EMC} 1 ;
$$

The relationship model between control variables (gender, education, income, and age) and employee task performance is shown in Equation 3.

$\mathrm{TP}=\alpha_{3}+\beta_{31} \mathrm{SEX}+\beta_{32} \mathrm{EDU}+\beta_{33} \mathrm{AGE}+\beta_{34} \mathrm{INCOME} ;$

The relationship between control variables (gender, education, income, and age), negative error management climate, and employee task performance is shown in Equation 4.

$\mathrm{TP}=\alpha_{4}+\beta_{41} \mathrm{SEX}+\beta_{42} \mathrm{EDU}+\beta_{43} \mathrm{AGE}+\beta_{44} \mathrm{INCOME}+\beta_{45} \mathrm{EMC} 2 ;$

Note: $\alpha$ is a constant term, $\beta$ is a standardized regression coefficient, SEX is gender, EDU is education level, AGE is year old, INCOME is monthly income level, EMC1 is a positive error management climate, and EMC2 is a negative error management climate.

The variables' VIF of each model is less than 10, indicating that the effect of multicollinearity between variables is not serious. As can be seen from Table 4 , gender $(\beta=-0.089, \mathrm{t}=-3.253, \mathrm{p}<0.05)$, age $(\beta=0.059, \mathrm{t}=2.152, \mathrm{p}<0.05)$ and monthly income level $(\beta=0.150, t=5.608, p<0.001)$ has a significant impact on situational performance. The positive error management climate has a significant positive impact on situational performance $(\beta=0.494, \mathrm{t}=21.513, \mathrm{p}<0.001)$, which is consistent with the results of Pengcheng Du and Zhiqiang Huang [6]. As can be seen from Table 5, the monthly income level $(\beta=0.117, \mathrm{t}=4.337, \mathrm{p}<0.001)$ has a significant positive impact on task performance. The negative error management climate has a significant positive impact on task performance $(\beta=0.343, \mathrm{t}=13.722, \mathrm{p}<0.001)$, and $\mathrm{H} 1$ and $\mathrm{H} 2$ are verified.

Table 4: EMC1 and CP regression analysis results

\begin{tabular}{|c|c|c|c|c|c|}
\hline \multirow{3}{*}{ Variables } & \multicolumn{4}{|c|}{$\mathrm{CP}$} & \multirow{3}{*}{ Hypothesi } \\
\hline & \multicolumn{2}{|c|}{ Model 1} & \multicolumn{2}{|c|}{ Model 2} & \\
\hline & $\beta$ & $\mathrm{t}$ & $\beta$ & $\mathrm{t}$ & \\
\hline Gender & $-0.089^{*}$ & -3.253 & $-0.061^{*}$ & -2.590 & \\
\hline Education & 0.003 & 0.107 & 0.037 & 1.568 & \\
\hline Age & $0.059^{*}$ & 2.152 & $0.124^{* * *}$ & 5.142 & \\
\hline Income & $0.150^{* * *}$ & 5.608 & $0.147^{* * *}$ & 6.332 & \\
\hline EMC1 & & & $0.494^{* * *}$ & 21.513 & H1 \\
\hline $\mathrm{R}^{2}$ & 0.040 & & 0.280 & & \\
\hline $\mathrm{F}$ & $14.653^{* * *}$ & & $108.166^{* * *}$ & & \\
\hline$\Delta \mathrm{R}^{2}$ & & & 0.240 & & \\
\hline
\end{tabular}

Note: $\mathrm{N}=1400 ; * \mathrm{p}<0.05, * * \mathrm{p}<0.01, * * * \mathrm{p}<0.001$ 
The Impact of Error Management Climate on Employee Performance

Table 4: EMC2 and TP regression analysis results

\begin{tabular}{cccccc}
\hline & \multicolumn{4}{c}{$\mathrm{TP}$} & \multirow{2}{*}{ Hypothesis } \\
\cline { 2 - 5 } Variables & \multicolumn{2}{c}{ Model 4 } & \multicolumn{2}{c}{ Model 5 } & \\
& $\beta$ & $\mathrm{t}$ & $\beta$ & $\mathrm{t}$ & \\
Gender & -0.031 & -1.136 & -0.012 & -0.476 & \\
Education & 0.043 & 1.590 & $0.060^{*}$ & 2.332 & \\
Age & 0.019 & 0.683 & 0.039 & 1.487 & $\mathrm{H} 2$ \\
Income & $0.117^{* * *}$ & 4.337 & $0.128^{* * *}$ & 5.030 & \\
EMC2 & & & $0.343^{* * *}$ & 13.722 & \\
$\mathrm{R}^{2}$ & 0.020 & & 0.136 & & \\
$\mathrm{~F}$ & $6.977^{* * *}$ & & $43.990^{* * *}$ & & \\
$\Delta \mathrm{R}^{2}$ & & & 0.116 & & \\
\hline
\end{tabular}

Note: $\mathrm{N}=1400 ; * \mathrm{p}<0.05, * * \mathrm{p}<0.01, * * * \mathrm{p}<0.001$.

\section{Conclusions and prospects}

\subsection{Conclusions and recommendations}

In the Chinese context, this study analyzes and verifies the impact of the organization's error management climate on employee performance, expands the theory of error management and performance management, and improves research in this field. The study found that the positive error management climate is conducive to contextual performance, and the negative error management climate is conducive to task performance.

For management practice, firms should take various measures to transform the error experience into valuable resources for employees and enterprises, and thus promote the improvement of employee performance. (1) Firms need to develop a reasonable error management system. Firms can incorporate the spirit of flexibility, tolerance and exploration into the culture and climate of the organization, create an informal error communication environment, and promote mutual help behavior among employees, in order to improve the contextual performance of employees. (2) The firms can implement a serious error management culture, in order to promote employees to abide by the rules and regulations, to learn excellent error cases, to improve the efficiency and quality of employees, and further to improve the task performance of employees.

\subsection{Deficiency and outlook}

As for the prospects of our research, this paper does not consider the factors affecting employee performance in terms of research framework. Relevant research shows that organizational support and organizational identity have an impact on employee performance [3]. Future research can add variables such as organizational support and organizational identity and so on. In terms of research methods, this paper only selects the method of horizontal data. The impact of error management climate on employee performance may have "time lag effect". Future research may use vertical research and case study. besides, the error management climate also exists at the organizational and team level. Future research can explore the impact of error management climate on employee performance across the level [3]. 


\section{Yin-ping Guan, Liang-ru Yu and Chong-li Wang}

\section{REFERENCES}

1. D.D.Johnson and D.T.Blumstein, Fowler J H, et al. The evolution of error: error management, cognitive constraints, and adaptive decision-making biases, Trends in Ecology \& Evolution, 28(8) (2013) 474-481.

2. C.van Dyck, M.Frese, M.Baer and S.Sonnentag, Organizational error management culture and its impact on performance: a two-study replication, Journal of Applied Psychology, 90(6) (2005) 1228-1240.

3. P.C.Du, M.Li and C.C.Wang, Research on the effect mechanism of error aversion culture on employees' dual performance, Economic Management, 39(5) (2017) $101-114$.

4. L.S.Fruhen and N.Keith, Team cohesion and error culture in risky work environments, Safety Science, 65(2) (2014) 20-27.

5. Y.J.Zhu and T.Bai, The impact of error management culture on organizational performance_- taking organizational innovation as a mediator, Science \& Technology Progress and Policy, 28(16) (2011) 1-4.

6. P.C.Du and Z.Q.Huang, The influence mechanism of error management culture on dual performance-based on the mediation effect of organizational identification, Journal of Anhui University (Philosophy and Social Sciences Edition), 40(06) (2016) 148-156.

7. B.Zhao and F.Olivera, Error reporting in organizations, Academy of Management Review, 31(4) (2006) 1012-1030.

8. N.Keith and M.Frese, Enhancing firm performance and innovativeness through error management culture, In Ashkanasy N, Wilderom P M C, Peterson F M (eds.), he Handbook of Organizational Culture and Climate (2nd Edition), SAGE Publications, Thousand Oaks, CA, (2011) 137-157.

9. A.Gold, U.Gronewold and S.E.Salterio, Error management in audit firms: Error climate, type, and originator, The Accounting Review, 89(1) (2014) 303-330.

10. U.Gronewold, A.Gold and S.E.Salterio, Reporting self-made errors: The impact of organizational error-management climate and error type, Journal of business ethics, 117(1) (2013) 189-208.

11. W.C.Borman and S.J.Motowidlo, Expanding the criterion domain to include elements of contextual performance. Personnel Selection in Organization, San Francisco, CA: Jossey-Bass, (1993).

12. H.Wang, X.X.Li and S.Q.Luo, The distinction of task performance and contextual performance and their effects on work outcomes, Chinese Journal of Management Science, 11(4) (2003) 79-84.

13. S.J.Motowidlo and J.R.Van Scotter, Evidence that task performance should be distinguished from contextual performance, Journal of Applied Psychology, 79(4) (1994) 475-480.

14. J.A.Lepine and L.Van Dyne, Voice and cooperative behavior as contrasting forms of contextual performance: Evidence of differential relationships with Big Five personality characteristics and cognitive ability, Journal of Applied Psychology, 86(2) (2001) 326-336.

15. V.I.Coleman and W.C.Borman, Investigating the underlying structure of the citizenship performance domain, Human Resource Management Review, 10(1) (2000) 25-44. 
The Impact of Error Management Climate on Employee Performance

16. B.Zhao, Learning from errors: The role of context, emotion, and personality, Journal of Organizational Behavior, 32(3) (2011) 435-463.

17. Y.Liu, U.Adam and W.D.Schareck, Impact of organizational culture on employees job performance: an empirical study of software houses in pakistan, Journal of Business Studies Quarterly, 36(4) (2013) 1125-1126.

18. C.Argyris and C.Schon, Organizational Learning: Theory, Methodology and Practice. II, Renmin University of China Press, (2011).

19. Y.J.Zhu and Y.Yu, The influence of error management culture and psychological empowerment on employee innovative behavior: the moderating role of creative self-efficacy, China Human Resources Development, (17) (2014) 23-29.

20. Y.Li and L.Ma, Research on the impact mechanism of error management climate on knowledge conversion process, Information Studies: Theory \& Application, 37(02) (2014) 57-60.

21. L.Ma, Research on The relationship between error management climate, knowledge transformation and employee ability, Chongqing University of Posts and Telecommunications, (2015).

22. G.Q.Chen, An empirical study of the relationship of psychological safety, team learning capacity and team performance, Studies in Science of Science, 16(1) (2008) 147-157.

23. A.S.Tsui, J.L.Pearce, L.W.Porter, and A.M.Tripoli, Alternative approaches to the employee-organization relationship: Does investment in employees pay off? Academy of Management Journal, 40(5) (1997) 1089-1121.

24. J.T.Hou, Z.L.Wen, and Z.J.Cheng, Structural Equation Model and its Application, Economic Science Press, (2004). 